\title{
OBSERVATIONS ON THE VITALITY OF THE NEWBORN
}

\author{
BY \\ F. E. HYTTEN* \\ From the Department of Midwifery, University of Aberdeen
}

(Received for Publication February 14, 1951)

Vitality, defined in the dictionary as ' the capacity to thrive and endure,' is a summation of all assimilative, metabolic, circulatory, and protective functions. It can be measured crudely, in large groups, by mortality and morbidity rates, but since such rates are determined by the reaction between groups of individuals and a variable environment, they may be difficult to interpret. Some observers (Stuart, 1945) used measures such as size at birth or degree of osseous development in an attempt to demonstrate differences of quality in infants, but size and stage of development are not necessarily correlated with efficiency of function. Baird (1949) has posed the question, "How does one tell whether a particular baby is more vital than another?' Some measure is necessary if we are to correlate vitality with the mother's health and diet during pregnancy. Some idea may be obtained by noting the presence or absence of foetal distress during labour and the child's behaviour after birth. The vigour of its movements is difficult to measure, and its ability to suck depends on the type of breast and nipples, the milk supply, and the efficiency of the mother and nurse.

General clinical assessment of vitality is highly subjective and hence has limited scientific value. It was considered that objective assessment of the more accessible neonatal reflexes might be useful. The interpretation of tests carried out during the first week of life should not be unduly complicated by the influence of the general extra-uterine environment. This paper deals with the sucking reflex, the grasp reflex, muscular power, and power of coordinating upper limb action. The first of these is bound up with ability to obtain nourishment and the others are probably associated with the ability of a baby to protect itself. Performance on test, therefore, should have some relationship to the 'capacity to thrive and endure.'

Initial studies were made of 100 unselected normal

\footnotetext{
- Walter and Eliza Hall travelling research fellow.
}

infants, followed by studies of 80 normal offspring of primiparae. A ' normal' infant was defined as one weighing more than $5 \frac{1}{2} \mathrm{lb}$. at birth, without any obvious physical abnormality, and requiring no more than routine care in the lying-in wards of a maternity hospital.

\section{Methods}

Sucking Reflex. Fig. 1 shows the apparatus used here. An Allenbury-type teat was connected by $2 \mathrm{~mm}$. bore pressure tubing, both to a recording manometer and to a milk supply. The hole in the teat was large (4-5 mm. diameter) and was cut irregularly so that it could not be sealed off by the infant's tongue. Corrugated rubber was placed in the teat cavity to prevent collapse. The manometer itself had a constriction in the base of the U-tube to counter the effect of inertia of the mercury. The actual response of the mercury to sudden load and release is shown in the standardization curve (Fig. 2). With this response, the manometer was found to be sensitive enough to the relatively slow rhythm of sucking. Waste space in the apparatus was reduced to less than $10 \mathrm{ml}$. by keeping connecting tubes narrow and short. Warmed milk was supplied from a reservoir and the flow regulated $5-10 \mathrm{ml}$. a minute by means of a drip-feed system controlled by a screw clamp.

Up to the fourth day of life the majority of infants would suck a dry teat for some minutes without tiring, and could not cope with more than about $1 \mathrm{oz}$. of milk a minute without choking. After the fourth day most infants refused to suck for more than 10 to 20 seconds without reward, and were able to handle milk flows up to about 1 oz. a minute without choking.

It was found that the sucking response of infants remained constant when the temperature of the milk was maintained between $20^{\circ}$ and $40^{\circ} \mathrm{C}$. (confirming Jensen, 1932) and over a wide range of rates of milk flow. Careful tests were carried out on six infants to see if the response on the apparatus resembled that on the breast. During breast-feeding a tube connected to the manometer was inserted into the corner of the infant's mouth. Performances at the breast were found to be indistinguishable from those on the apparatus.

Records were taken on the second, fourth, sixth and eighth days of life, during the fourth hour after a feed, 


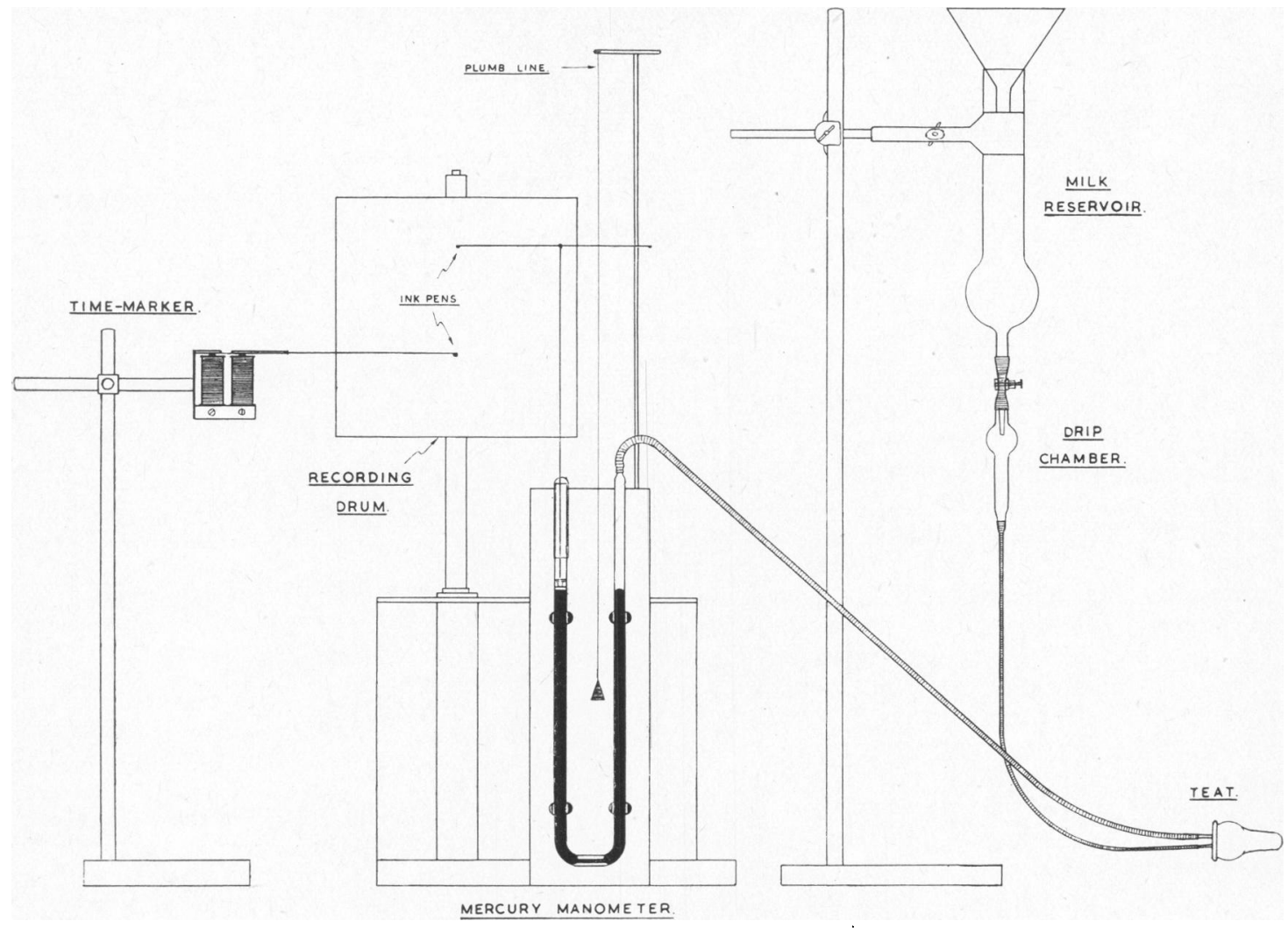

Fig. 1.-Sucking apparatus.

STANDARDIZATION

$-50 \mathrm{MM} . \mathrm{HG}$
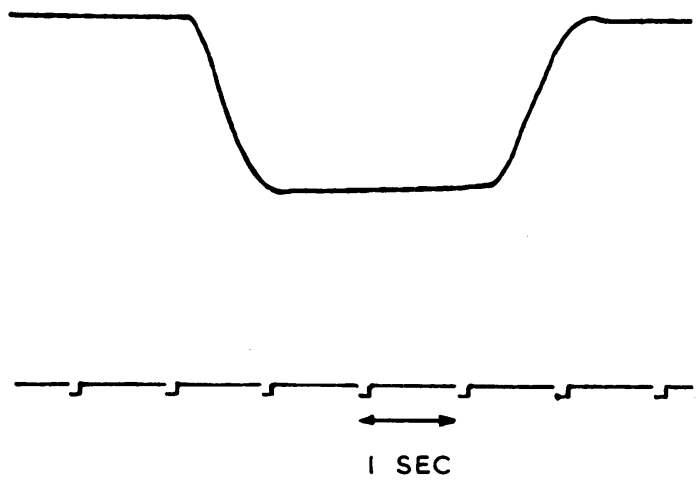

FIG. 2.-Standardization of manometer by sudden decrease of pressure to $-50 \mathrm{~mm}$. $\mathrm{Hg}$ followed by sudden release to atmospheric pressure. usually just before the $2 \mathrm{p} . \mathrm{m}$. or $6 \mathrm{p} . \mathrm{m}$. feeds. The first four minutes of sucking were recorded, as it is recognized that the bulk of a breast feed is obtained in this time (Smith and Merritt, 1922).

Tracings could be differentiated in terms of average sucking pressure, maximum sucking pressure, time during which active sucking was in progress, and time during which a negative pressure was maintained with or without sucking movements. In a typical record, the infant begins to suck at once, with a flourish, and after 15 to 30 seconds settles down to a steady sucking rhythm, half or three-quarters as great as its original maximum. Active sucking and swallowing might be maintained for anything from 10 to $100 \%$ of the total duration of the record. It should be noted (Fig. 3) that sucking and swallowing excursions take place not from the line of atmospheric pressure but from a line of mean negative pressure determined by the individual infant. Sucking and swallowing can usually be differentiated. Sucking is associated with a relatively small swing of the mercury, usually about $10 \mathrm{~mm}$.; in swallowing, the swing becomes two or three times larger. A swallow appeared to take place after about four or five sucks when the milk flow was small, but as the milk flow was increased there might be a swallow after each suck, or even continuous 
A

B

C

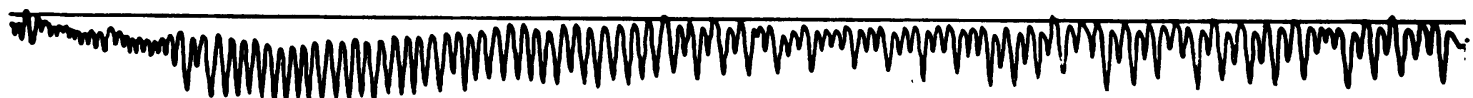

FIG. 3.-Tracing of intra-oral pressure showing A, sucking; B, swallowing; and C, mixed sucking and swallowing.

2ND. DAY: M.E.P. $=10.5 \mathrm{MM} . \mathrm{HG}$

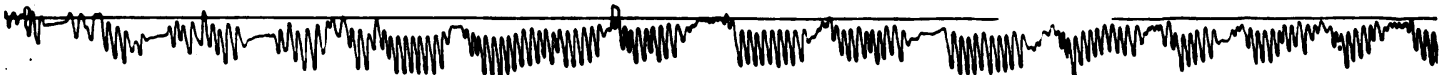

4TH. DAY: M.E.P. $=11.5 \mathrm{MM} . \mathrm{HG}$

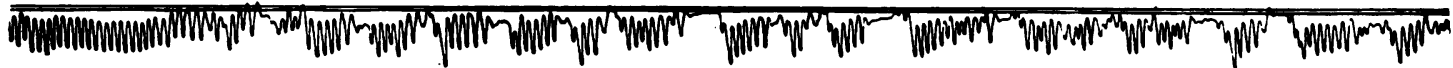

6TH.DAY: M.E.P. $=11.5 \mathrm{MM} . \mathrm{HG}$

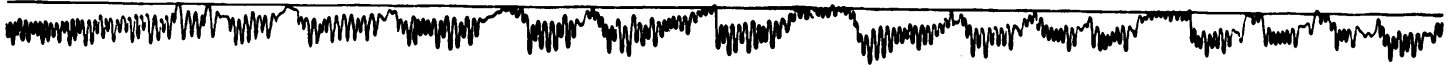

8TH.DAY: M.E.P. $=12 \mathrm{MM} . \mathrm{HG}$

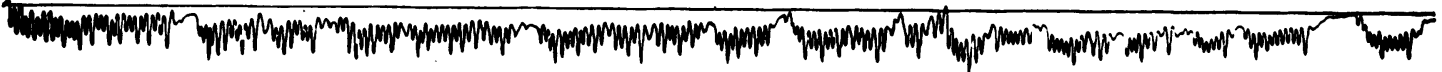

Fig. 4.-Four successive tracings of one infant demonstrating constancy of performance.

(M.E.P. $=$ mean effective pressure.)

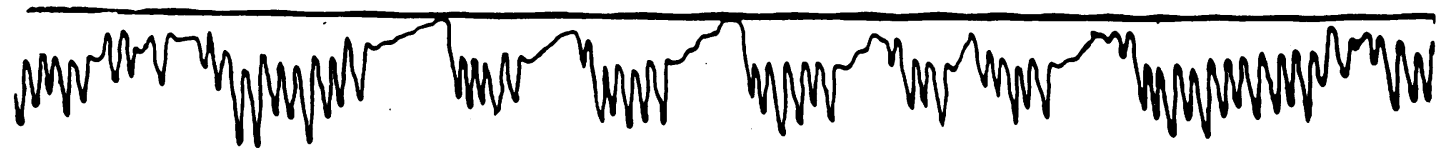

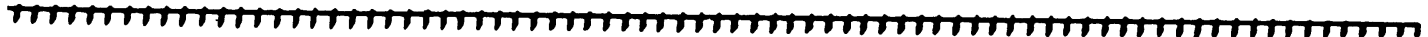

FIG. 5.-Section of tracing demonstrating the slow fall in 'suction' pressure in the mouth as it fills with milk during a pause. 
swallowing. Uninterrupted sucking and swallowing was not usual, and, as a rule, the tracing was broken up into periods of activity lasting 10 to 20 seconds, separated by intervals of one or two up to 20 seconds, during which pressure slowly regained atmospheric pressure as the mouth filled with milk, or suddenly if the mouth opened. Four out of every five babies sucked and swallowed actively for between 60 and $90 \%$ of the recording time, and in nine-tenths of the cases some degree of negative pressure was maintained for $70 \%$ or more of the time.

Figs. 3, 4, and 5 show some typical tracings. It was found that most infants gave a characteristic tracing on all four test days. The pattern of sucking was more constant than the actual mean pressure. In $66 \%$ of cases the mean effective pressure (M.E.P.) did not vary by more than $2 \mathrm{~mm} . \mathrm{Hg}$ in trials over the four test days; $24 \%$ of cases improved by more than $2 \mathrm{~mm}$. $\mathbf{H g}$, $4 \%$ deteriorated, and $6 \%$ gave haphazard results. The liability to improve or remain steady was not associated with the normal supply of breast milk or with bottle feeding (Table 1).

Several ways of evaluating the tracings were studied, and the best was found to be the mean effective pressure (M.E.P.) of the whole record. The value of M.E.P. is obtained from the formula

(Area enclosed by tracing and by line representing atmospheric pressure) $\times 2$

(Length of tracing)

The area is measured with a planimeter. The factor 2 is used because one limb of a manometer records pressures at half their true value. M.E.P. thus takes into account both the average degree of suction and the proportion of recording time during which suction is maintained. The value is not materially affected by the amount of swallowing. As used hereafter, it refers to the mean of four measurements made on the second, fourth, sixth, and eighth days of life. It should be noted that the pressure is negative. To avoid confusion and complication, the negative sign will be omitted and greater or lesser M.E.P. will refer to greater or lesser degrees of negative pressure or suction.
The values of M.E.P. for the 180 normal infants were normally distributed around a modal point at $10 \mathrm{~mm} . \mathrm{Hg}$ (Fig. 6). Extremes of $2 \mathrm{~mm}$. and $26 \mathrm{~mm}$. were recorded,

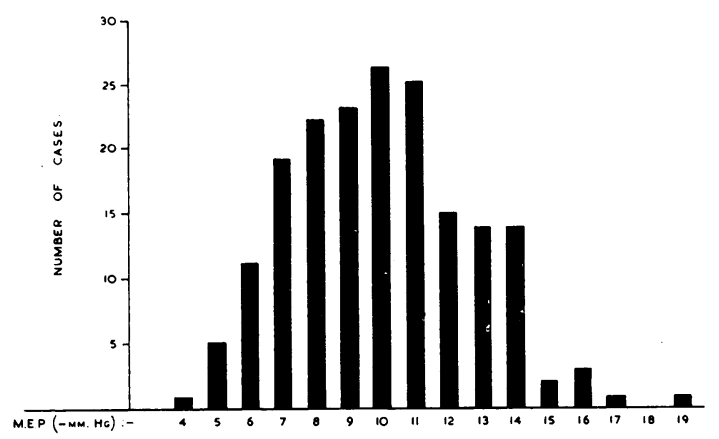

FIG. 6.-Frequency distribution of mean effective pressure in 180 cases.

both in abnormal cases. The greatest M.E.P. recorded in a normal infant was $22 \mathrm{~mm}$.

Other authors have evaluated the sucking effort in terms of the greatest negative pressures recorded. Cramer (1900) and Gunther (1945) obtained negative pressures up to $70-200$ and $45-100 \mathrm{~mm}$. $\mathrm{Hg}$ respectively. In the present study no suction greater than $50 \mathrm{~mm}$. $\mathrm{Hg}$ has been recorded. It is probable that higher values reported by other workers were obtained by the use of faulty apparatus. I was able to obtain similarly high values by using an undamped manometer and a pin-hole teat (Fig. 7). It seems that if the mercury can oscillate relatively violently and if the infant's tongue can seal off the teat or tube, a valve-like action causes negative pressure to build up in the apparatus until it greatly exceeds the true intra-oral pressure.

Grasp Reflex. The attempt was made to induce infants to grasp a thin, rubber-covered rod attached to a spring balance, with the idea of measuring the pull required to break the grip. The method had to be

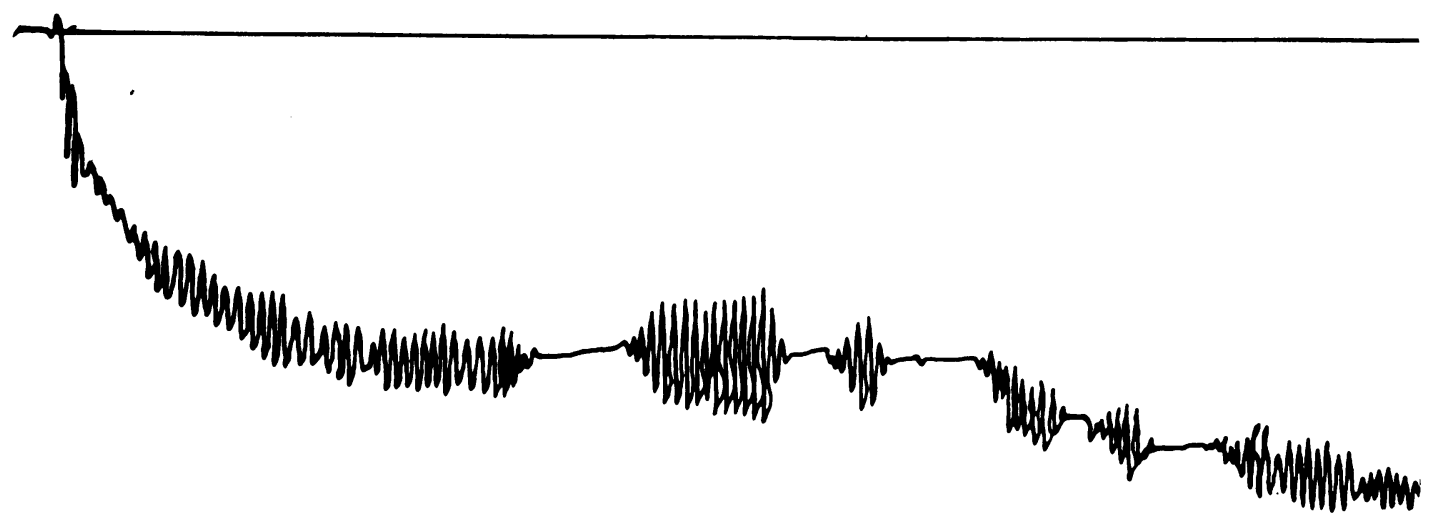

Fig. 7.-The effect of an undamped manometer used in conjunction with a 'pin-hole' teat. Maximum pressure shown is $-130 \mathrm{~mm}$. $\mathrm{Hg}$. 


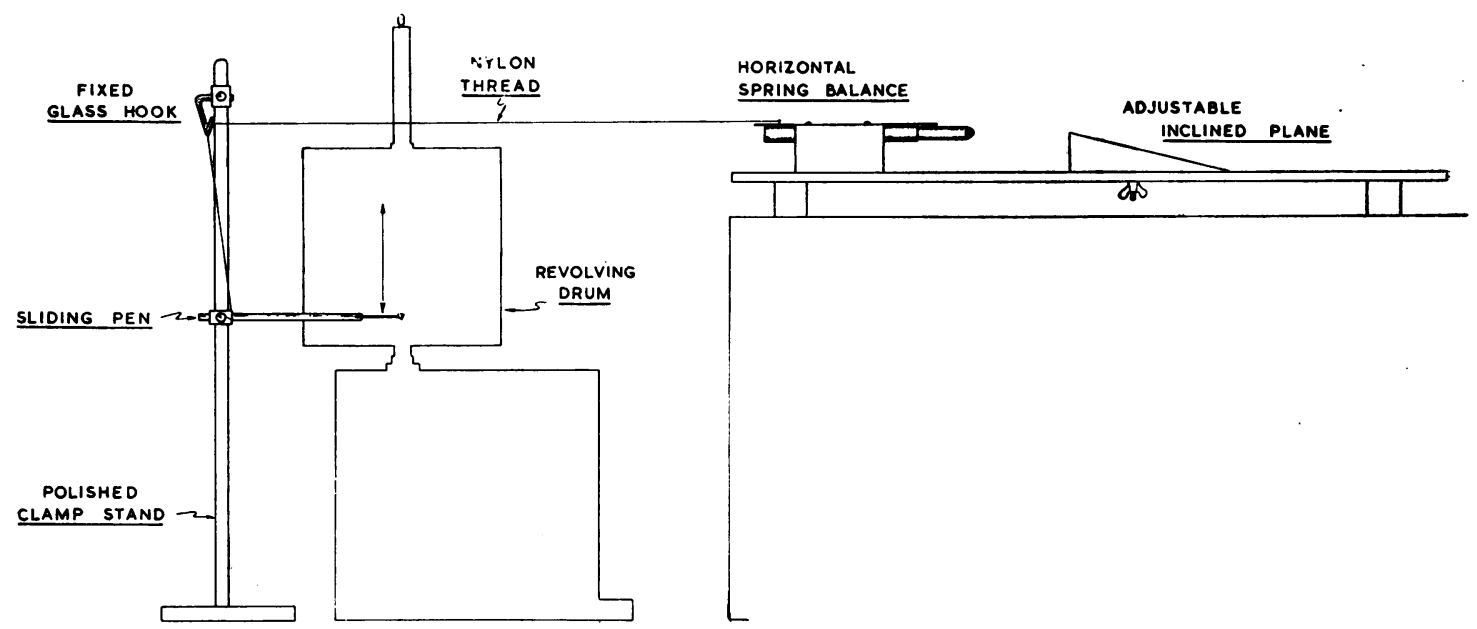

FIG. 8.-Apparatus for recording pull factor.

abandoned, because many infants were uncooperative and because results, when obtained, appeared to be completely haphazard. No results are therefore presented.

Muscular Power. The infant was placed on a table with its lower limbs extended by hand pressure to slightly less than full extension at the knee. Anklets were tied on, and tapes from them fixed to a horizontal spring balance giving about $\frac{1}{2}$ in. movement per lb. A cold object placed on the infant's chest invariably caused a forcible flexion of the lower limbs. For the first 100 cases the strength of the pull was measured by placing a 'rider' beside the marker on the spring balance, which remained at the highest figure obtained. For the final 80 cases (for reasons given below). it was found desirable to take into account both the average strength of the pull and the time during which it was maintained, and this was done by attaching the marker of the spring balance by a cord over a pulley to a recording drum (Fig. 8). With this new apparatus continuous cold stimulation was applied to the infant's chest and recording was discontinued when the record fell back to $1 \mathrm{lb}$. weight or less.

The following values obtained from these records were used: (a) the 'muscular power index,' which is simply the greatest pull exerted, expressed as a percentage of body weight; and (b) the 'pull factor,' which is the product of the time in seconds during which active contraction was present and the average tension exerted during this time, expressed as a percentage of body weight. Fig. 9 shows a typical tracing.

Coordination. In all 180 cases the tip of the infant's nose was held lightly and its reactions observed. On a first trial most infants thrashed wildly with all four limbs, shook their heads, and occasionally responded by mass extension. A very few made an apparently deliberate attempt to remove the hand. On succeeding trials some infants quickly learnt to remove the nuisance by using their upper limbs, while others took longer. The observer's fingers were removed from the infant's nose immediately the infant struck the hand. Response was graded as follows:

'Very good' if there was an apparently deliberate attempt to brush away the observer's hand within 5 seconds

'Good' if the attempt was made between 5 and 15 seconds .. ..

- Fair' if between 15 and 30 seconds .

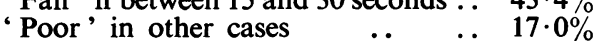

Each infant was required to repeat the performance at least once, and usually twice, at each trial.

Other Data. The following specific information was available for all or some of the infants tested:

Clinical Grading. The first 100 infants were graded independently by three independent assessors who were given the following information: the physical state of the infant immediately following birth; the muscle tone and general physical appearance; the activity reaction to stimulation; any clinical observations during the first

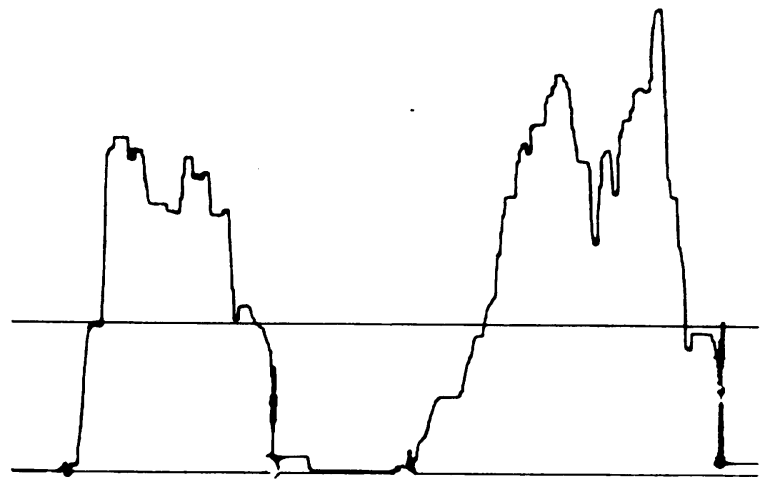

Fig. 9.-Two typical recordings of pull factor. The first infant gives an average pull of $2 \cdot 2 \mathrm{lb}$. for nine seconds and the second infant an average pull of $2.6 \mathrm{lb}$. for 14 seconds before falling to the ' $1-1 \mathrm{~b}$.' line. 


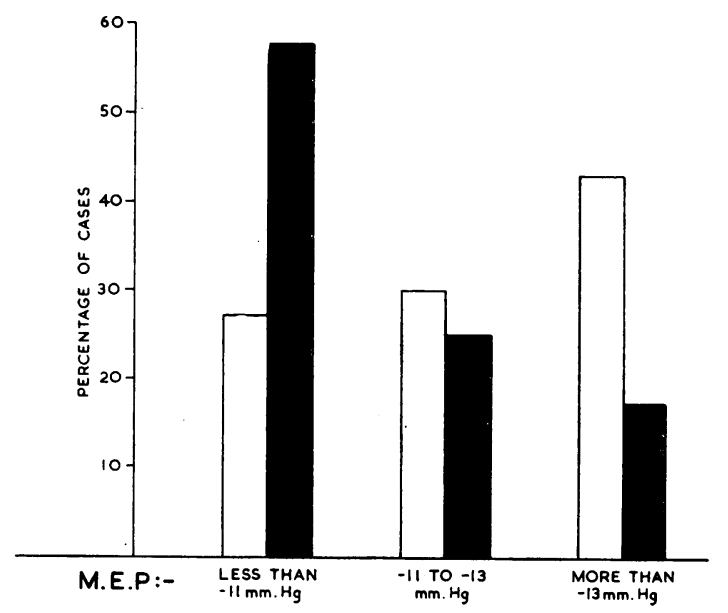

EFFICIENT ( 44 CASES) - MEAN $=12.545$
BABIES

INEFFICIENT (40 CASES) - MEAN $=10.475$
BABIES

Fig. 10.-Distribution of ' efficient and inefficient ' babies arranged according to sucking performance. week of life, e.g. difficulties with 'mucus,' jaundice, and cyanosis; the feeding performance as judged by test weighing; and the weight curve.

Naturally, there were variations in the grading of individual infants by each assessor, but in no case did the three assessors place any infant in three different grades. In $42 \%$ of cases all three assessors agreed completely. In the remainder, the majority verdict was used. The distribution obtained was:

$$
\begin{aligned}
& \begin{array}{llllll}
\text { Very good } & \ldots & \ldots & \ldots & \ldots & 14 \%
\end{array}
\end{aligned}
$$

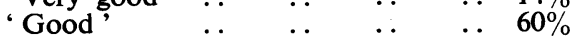

$$
\begin{aligned}
& \begin{array}{llllll}
\text { 'Fair, } & . & . & . . & \ldots & 60 \% \\
& . & . & . . & . . & 22 \%
\end{array} \\
& \begin{array}{lllllr}
\text { 'Poor, } & . & \ldots & \ldots & \ldots & 22 \% \\
& & & &
\end{array}
\end{aligned}
$$

The relatatively close agreement obtained was doubtless partly due to the fact that the three clinicians concerned have worked in the same unit for some time and have many standards in common.

Milk-getring Capacity. The first 100 infants were divided arbitrarily into two groups. 'Efficient' infants were those who obtained $2 \cdot 2 \mathrm{oz}$. (63 ml.) breast milk per $\mathrm{lb}$. body weight in 24 hours before the tenth day, or alternatively emptied both breasts so thoroughly that no more than 4-5 $\mathrm{ml}$. could be expressed after feeding. 'Inefficient' were those who obtained less than $2 \cdot 2 \mathrm{oz}$.

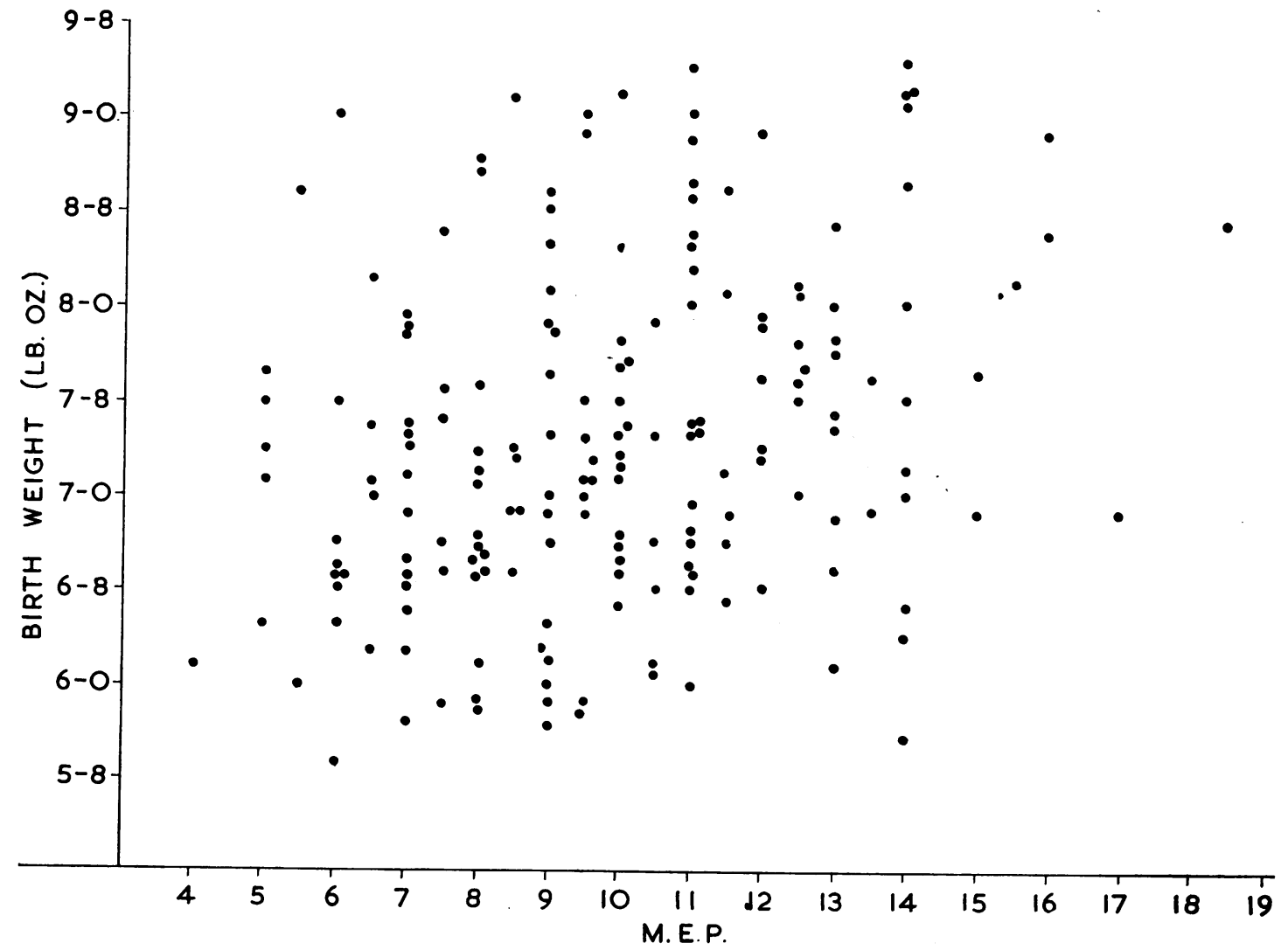

FIG. 11.-Correlation of birth weight and M.E.P. $(r=0.30 \mathrm{P}>0.001<0.01)$. 
(63 ml.) per lb. body weight in 24 hours and left milk in the breast.

(The value of $2 \cdot 2 \mathrm{oz}$. $(63 \mathrm{ml}$.) was chosen because it divided the cases into two groups of roughly equal size.)

BiRTH WEIGHT. The birth weight of all infants was noted.

Composition of Breast MiLk. Milk of the seventh day post-partum was expressed manually for 24 hours, and samples of the pooled yield were analysed for fat, protein, and lactose in 60 of the final cases.

\section{Results}

M.E.P. was evaluated with milk-getting capacity. Fig. 10 shows that babies who emptied the breasts or who got more than $2 \cdot 2 \mathrm{oz}$. milk per lb. body weight by the tenth day were, on the whole, more powerful suckers, as assessed by M.E.P. The correlation is highly significant $(P .<\cdot 001)$.

It might be argued that heavier babies had greater ability to suck as well as a better milk supply, so that

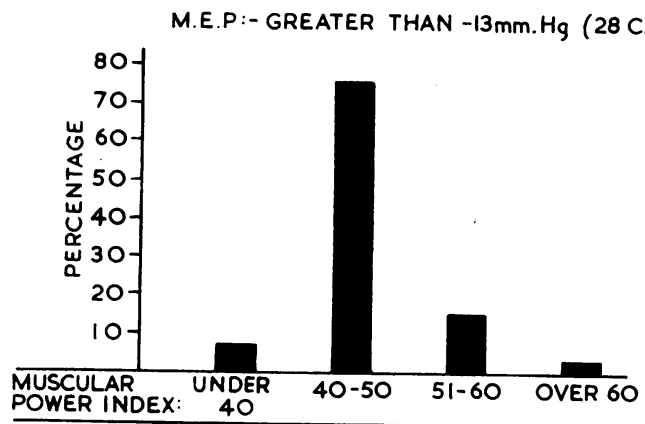

M.E.P:- -11 TO $-13 \mathrm{~mm} . \mathrm{Hg}$ (28 CASES)

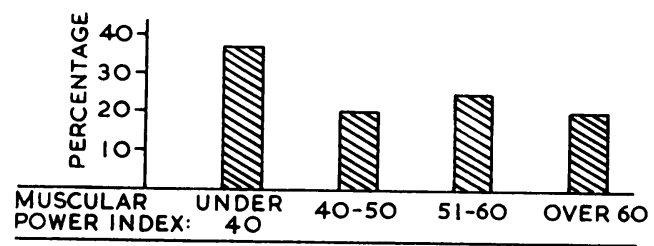

M.E.P:- LESS THAN $-11 \mathrm{~mm} . \mathrm{Hg}$ (44 CASES)

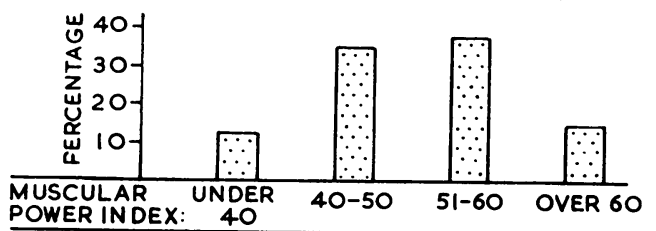

FIG. 12.-Frequency distribution of muscular power index in infants, arranged in three groups for M.E.P. this correlation might be to some extent fortuitous. Birth weight and M.E.P. are correlated to a slight degree (Fig. 11) but not birth weight and milkgetting capacity. The correlation between M.E.P. and milk-getting capacity would appear, therefore, to be independent of birth weight.

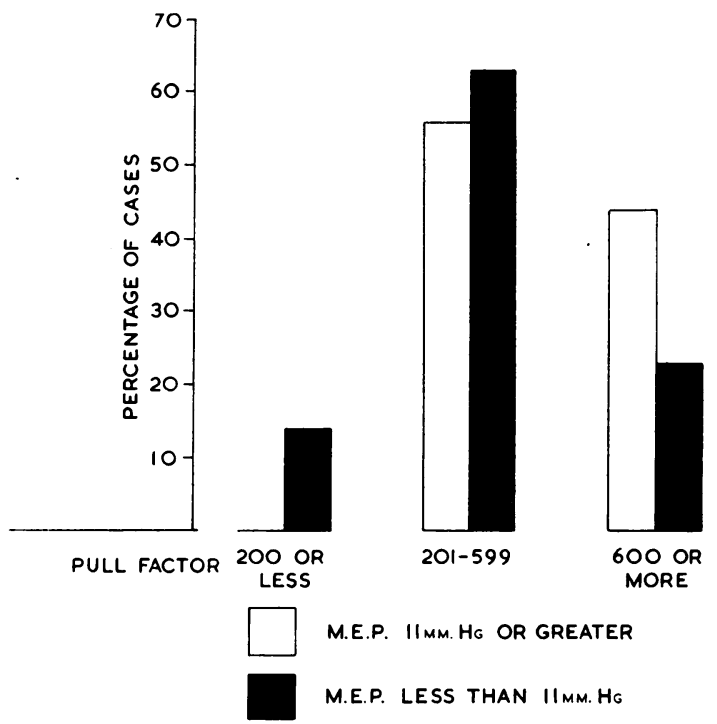

FIG. 13.-Correlation between M.E.P. and pull factor.

M.E.P. was inversely correlated (significant at $1 \%$ level) with the fat content of the seventh day milk. The meaning of this curious finding is not clear. There was no correlation between M.E.P. and seventh day milk volume, nor with milk constituents other than fat.

In the first 100 cases it was found that M.E.P. and muscular power index were negatively correlated to a significant degree. Fig. 12 shows that among babies with a high M.E.P. the muscular power indices tended to be concentrated between 40 and 50 whereas with lower M.E.P. levels the scatter was very much wider. A possible interpretation of this distribution is that the former group of babies gave more sustained and purposeful flexion of the lower limbs under test, whereas the latter tended to give ill-sustained but momentarily more powerful jerks. It was for this reason that time as well as strength of pull was measured and expressed as 'pull factor.' In the second series of 80 babies it was found that, whereas muscular power index and M.E.P. were again negatively correlated, M.E.P. and ' pull factor' were positively correlated (Fig. 13). Fig. 14, however, shows this correlation to be low. The pull factor is probably, therefore, a better measure of muscular action. 
The values of pull factor obtained did not seem to be related to muscle tone as assessed clinically. Their importance, if any, can only be determined by a follow-up study to find out, for example, whether babies with better performance showed evidence of better locomotion later in growth.

Coordination, as tested, was found to be correlated significantly with the combined clinical assessment, but not with any other measure available in this series. The meaning of the test is not entirely clear, but apart from being a crude test of coordination of muscle action, it may have some relation to a baby's ability to learn.

The various tests did not necessarily agree with one another in a given case. The reason may be that different kinds of function may not be equally developed. Not enough work has been carried out to show definitely which test is the most useful in assessing vitality. The human infant is, however, not expected to do much more than feed itself, and survives without the need for self-protection. For this reason, the M.E.P. should, theoretically at least, be the most useful index of vitality. The M.E.P. and coordination were positively correlated with the clinical grading of the first 100 infants, the correlations being significant at the $1 \%$ level. Muscular power index was negatively correlated, but its significance is doubtful. The correlations were, however, not high for individual babies. The clinical grade could be predicted in only about $75 \%$ of cases when a regression equation containing values of M.E.P. and coordination were used. This lack of correlation in many individual cases between the clinical assessment and the M.E.P. seems most likely to have been due to difficulties in grading babies clinically.

\section{Discussion}

The Sucking Reflex. Clinical evaluation of feeding is highly unreliable. Norval (1946) in a study of 50 infants, found that only $20 \%$ were vigorous feeders, and that $76 \%$ tended to fall asleep and required stimulation. Experience in this series indicates that the vigorous, busy-looking infant does not have the consistent performance of the relaxed infant, who may well be sucking thoroughly though sometimes apparently asleep. The weight curve is commonly used as a criterion of successful feeding, but cannot be reliable, since it represents a balance between the unknown caloric intake of the infant and its equally unknown metabolic level.

The sucking reflex is one of the earliest reflexes to appear, having been demonstrated as early as the third month in utero (Windle, 1940) so that there can be no question of absence through immaturity.

Most observers, however, maintain that 'sucking '

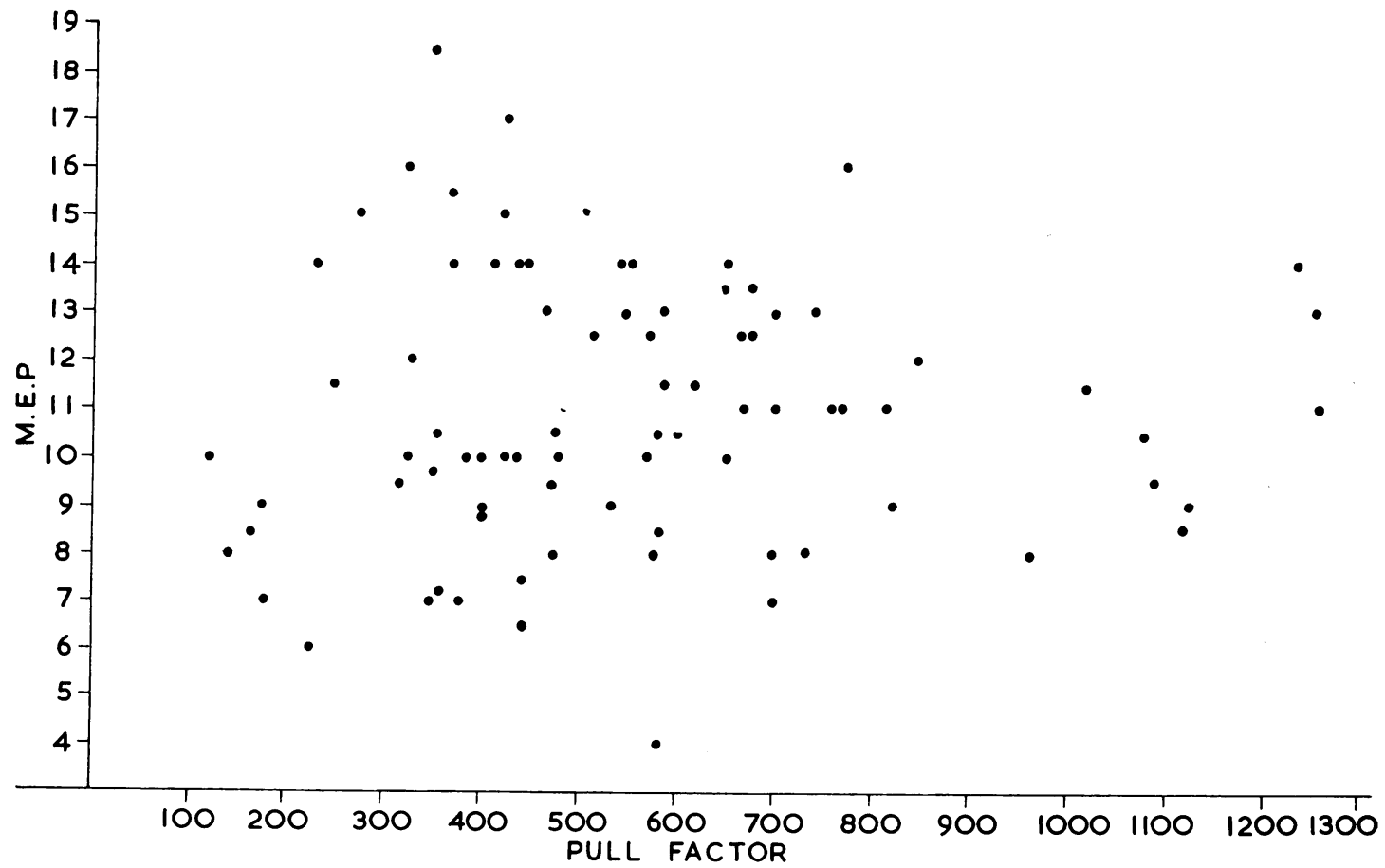

FIG. 14.-Correlation of M.E.P. and pull factor. 
as applied to feeding is a misnomer, and the actual force which extracts the milk is a type of oral expression carried out by the jaws. This idea has been firmly stressed in the literature for at least 50 years and in textbooks from Pfaundler and Schlossman in 1908 to Naish in 1948, but no real evidence is submitted.

Statements denying that sucking is the force which obtains milk from the breast have been punctuated, however, by work attempting to demonstrate the sucking potential of infants. On only one occasion has this been correlated with milk-getting capacity. Cramer (1900), by a method which he does not describe, gives actual pressures at which he maintains the breast begins to secrete milk, varying from $10 \mathrm{~mm}$. $\mathrm{Hg}$ to $-50 \mathrm{~mm}$. $\mathrm{Hg}$ for different breasts.

In the other studies, the sucking appears to have been considered in relation to other factors than feeding ability. Gunther (1945) was demonstrating a cause of cracked nipples, Jensen (1932) discrimination of taste and temperature sensation, and Kasahara (1916) was only interested in the variation of sucking pattern in normal and abnormal infants.

Theoretically, the sucking power of an infant is a valid index of the ability to remove liquid from a reservoir at atmospheric pressure, but it must be admitted that it does not necessarily reflect its ability to remove milk from the rather more complex human breast. However, some accessible and objective criteria of feeding ability are required, and sucking does seem to represent a reasonable starting point. It is, of course, possible that the infant might be influenced in its performance by its experience at the breast. For example, a baby with an initially low M.E.P. might, if nursed by a mother with freeflowing milk, learn to diminish its sucking performance without prejudice to its milk intake. Alternatively, the infant confronted by a scanty supply might exert itself and increase its performance in an attempt to better its intake.

Although Aldrich (1945) maintains that an infant exists on a purely subcortical level and cannot 'learn' habits, Marquis (1941) has shown that feeding schedules can be 'learned' in 10 days, and Fredeen (1948), who spoon-fed a series of infants from birth, states that the sucking reflex can be made to disappear entirely after one week. The possibility that an infant is able to learn from experience within the first week of life stimulated the investigation shown by Table 1 . There is no significant variation in M.E.P. which would indicate adaptation of sucking performance to the ease or difficulty of obtaining milk at least within the first eight days.

Measurement of Muscular Power. This application of the Moro reflex has not been previously described and it is reasonable to suppose that the method used will demonstrate the maximum power available from flexion of the lower limbs.

Knop (1946) carried out an experiment in which she lifted infants by their hands and attempted to grade the vigour of their reaction by the degree of spontaneous flexion at the elbow, but reached no significant results.

The use of the muscular power index admittedly gives an advantage to the leaner baby whose mass is composed of a higher proportion of muscle, but in the absence of the elaborate radiological techniques for the estimation of muscle mass, it is the only practicable method of bringing results to a comparable level.

The distribution of muscular power index in the first series of babies is striking. If the index occurring most frequently in the best suckers, that between 40 and 50 , is to be accepted as the 'ideal' or 'normal,' then it must also be accepted that an infant's muscular performance can not only be too weak but also too powerful. This is difficult to believe. A more reasonable interpretation would be that the answer lies not in the maximum contraction but in the way it is achieved. The moderate contraction might represent a more sustained and purposeful movement than the more powerful but momentary one. The results, using the power factor, lend weight to this hypothesis, that although the poorer sucking group have a more potent initial contraction, their power of sustained muscular contraction is less.

Coordination. I can find no reference to the use of this test in the literature.

Stirnimann (1937) discusses the reactions of infants having their hands in gloves and regards the movements associated with attempts to remove this irritation as instinctive.

The test itself not only demonstrates the ability of the infant to coordinate its upper limbs, but perhaps more importantly, shows its ability to learn from experience, a simple form of self protection.

Irwin (1942) has pointed out that there is no means at our disposal of assessing the mental prowess of an infant, but the ability to learn which has been mentioned in reference to sucking, may have this second significance. Whereas it may confuse the assessment of true potential sucking power, the ability to learn from the environment is a function which itself requires evaluation. In conclusion, it should be emphasized that this work merely points in the approximate direction of the answer to the problem. To find a satisfactory measure of vitality with which to correlate such things as maternal health and diet is inevitably a long and intricate task. 


\section{Summary}

In an attempt to find some objective index of vitality, which has been defined as 'the ability to thrive and endure,' four functions of the newborn normal infant have been studied.

The mean effective pressure of sucking is correlated with the milk-getting capacity of the infant, with a clinical grading of general vitality, and, to a lesser extent, with birth weight.

There is no apparent variation in sucking performance during the eight days following birth which can be attributed to difficulty in breastfeeding.

The muscular power index, which implies the maximum power developed by a single muscular contraction, is negatively correlated with sucking performance, but the pull factor, indicative of sustained muscular action, is positively correlated, demonstrating that the better suckers have a more sustained and apparently purposeful muscular action than the poorer ones. The degree of correlation is, however, low.

Coordination, which shows not only the power of actual coordination, but also the ability to learn, is correlated with the clinical index of general vitality, but not with the other objective measurements.

The grasp reflex was discarded as being far from fully understood, no certain method of elicitation being known and results being quite haphazard.

My thanks are due to Professor D. Baird, and the staffs of the Aberdeen Maternity Hospital and of the Midwifery Department of the University of Aberdeen for valuable assistance; to $\mathrm{Mr}$. $\mathrm{H}$. D. Griffith, of the Department of Natural Philosophy, and to Mr. M. H. Quenouille, of the Department of Statistics, for technical advice.
TABLE 1

Changes of Sucking Performance in Relation to TYPE OF FEEDING

\begin{tabular}{c|c|c}
\hline & $\begin{array}{c}\text { Steady* } \\
\text { Type of Milk Supply } \\
\text { (66 cases) }\end{array}$ & $\begin{array}{c}\text { Improvement } \\
\text { of } \\
\text { Performance } \\
\text { (24 cases) }\end{array}$ \\
\hline $\begin{array}{c}\text { Sufficient or more than } \\
\text { sufficient } \quad .\end{array}$ & $73 \%$ & $66 \%$ \\
\hline $\begin{array}{c}\text { Insufficient (complemen- } \\
\text { tary feeds given) }\end{array}$ & $25 \%$ & $25 \%$ \\
\hline $\begin{array}{l}\text { Artificially fed from } \\
\text { birth . . }\end{array}$ & $2 \%$ & $9 \%$ \\
\hline & $100 \%$ & $100 \%$ \\
\hline
\end{tabular}

*In 14\%' of 'steady' performers, and 13\% of 'improved' performers, there was some technical difficulty in feeding, due to inverted nipples, etc.

\section{REFERENCES}

Aldrich, C. A. (1945). Proc. Mayo Clin., 20, 60.

Baird, D. (1949). Lancet, 1, 1079.

Cramer, H. (1900). Dtsch. med. Wschr., 26, 32.

Fredeen, R. C. (1948). Pediatrics, 2, 544.

Gunther, M. (1945). Lancet, 2, 590.

Irwin, O. C. (1942). Psychol. Rev., 49, 69.

Jensen, K. (1932). Genet. Psychol. Monogr., 12, 361

Kasahara, M. (1916). Amer. J. Dis. Child., 12, 73.

Knop, C. (1946). J. Pediat., 29, 721.

Marquis, D. P. (1941). J. exp. Psychol., 29, 263.

Norval, M. A. (1946). Amer. J. Dis. Child., 71, 41.

Naish, F. C. (1948). ' Breast Feeding.' London.

Pfaundler, M., and Schlossman, A. (1908). 'Diseases of Children,' Vol. 1 (English Translation). Philadelphia.

Smith, C. H., and Merritt, K. K. (1922). J. Amer. med. Ass., 78, 1750.

Stirnimann, F. (1937). Rev. franc. Pédiat., 13, 496.

Stuart, H. C. (1945). Fed. Proc., 4, 271.

Windle, W. F. (1940). 'Physiology of the Fetus.' Philadelphia. 